pent-stone in "Tang-King." This was applied, stuck fast, absorbed the poison, dropped off, and the patient was freed. The stone was washed in lime-water, dried and could then be used again.

In a work on hydrophobia, published in 1812, Dr. Thacher says: "There prevails a fanciful opinion among a certain class of people, that a celebrated substance, known by the name of snake-stone, possesses, intrinsically, the power of extracting the poison of a snake or mad dog from the human body; that when applied, the stone will adhere like a leech to the bitten part, nor loose its hold till its numerous pores are literally glutted with the liquid poison. A case intended to corroborate this doctrine is recorded by Mr. William $\mathrm{H}$. Harding in the Medical Repository, Vol. 4, hex. 2. He relates that his child received a bite from a dog supposed to be affected with rabies. The snake-stone was applied (in due form and full faith no doubt) by which every particle of poison was extracted, and no ill consequences resulted from the accident. Dr. Mease has, in the Medical Museum (Vol. 5, p. 1) with his usual freedom and good sense, animadverted upon the unreasonable prejudice in favor of this popular but fallacious expedient. He informs us that in India such stones are very common, and the credulous natives believe, most firmly, in their preservative powers against the effects of the bites of venomous snakes. The author of the 'Wonders of Nature and Art,' says Dr. Mease, thus notices these stones in the account of Tonquin. 'Persons who happen to be bitten by serpents, press out the blood, and apply a small stone, called the serpent-stone, which is said to possess the miraculous power of drawing out the poison. When impregnated with the venom it drops off like a leech. It is then carefully washed with milk and water in which lime has been diluted, and on a second application to the wound, it exhales all the virus so completely, that in less than an hour, the pa. tient becomes perfectly free from pain.' 'Two of these stones,' adds Dr. M. 'are in the cabinet of the Philosophical Society. and another one is in my possession, all of which were brought last year by a gentleman from India. They are rather more than an inch long, and about five-sixteenths of an inch broad, of a bluish or slaty color and flattish shape." [Pp. 204-206.]

In 1801 Dr. Samuel Davis, of Petersburg, Va., wrote a letter to Dr. Benjamin Rush, which has never been published, but which is preserved in the Ridgway Branch of the Philadelphia Library. In this letter he describes a mad-stone which emitted bubbles when put in water after the application, and this was taken to be evidence that it had extracted the poison from the bite. The owner of this stone refused an offer of 300 guineas for it, a very large sum of money at that time. It was yellow, light and had many black pores. It had been given to the owner by a stranger who had been sick and cared for. It was wrapped in a printed paper, which declared "Francis Torres, a Native of France, is in possession of a chymical preparation, called a Chinese snake-stone, which will extract the poison of the bite of snakes, spiders, and of a mad $\operatorname{dog}$ and will cure cancers, which are sold at half a Guinea for the small and a Guinea for the large ones." This was dated Charlestown, S. C., 1740.

Mad-stones seem to be of two sorts: 1, some porous form of calcareous rock, or, 2, a concretion found in the intestinal canal of herbivorous animals, in this being like the Bezoar stone which figured so largely in the pharmacopeias of one hundred and fifty or two hundred years ago; in fact, it seems as though the mad-stone was indeed in many cases the Bezoar stone, which, when it ceased to be used in internal medication, came to be applied externally. There have been a number of so-called mad-stones in different parts of this country, most of them in the South and Southwest. In one case, in Virginia, the owner of a mad-stone in 1885 believed that it was the "talisman" sent by the Sultan as a wedding present on the occasion of the marriage of the Earl of Huntington to Edith Plantagenet.

Serious writers usually treat the mad-stone as having no specific virtue, but serving as a means to calm the apprehen. sions of those who have been bitten by rabid animals. I quite agree in this opinion, but am assured from my long-continued investigations of the subject of hydrophobia that in this re- spect it is not really inferior to some other modes of preventive treatment which have obtained the approval and support of men whose distinction in medicine is far greater than their industry in critically investigating the real worth of prophylactic measures which present themselves, with a pretentious air of scientific accuracy.

4101 Walnut Street.

Charles W. Dulles, M.D.

\section{Division of Fees.}

Chicago, April 29, 1900.

To the Editor:-For some time the surgeon and specialist have been giving their opinions as to the demands for fees and their division between the general practitioner and the operator. The view taken by the majority of specialists, that division of fees is dishonest and does the patient an injustice looks well in print and reads as though it were necessary for the specialist to guide the physician and correct his dishonest, grasping hand.

This controversy has been one-sided. And to show where the corruption is to be found I will state my own personal experience with the specialist. Within the last three years I have been approached by no less than three of the prominent and leading surgeons of Chicago who, openly and of their own free will, made these propositions to me: One said he would be pleased to do all my surgical work and give me 50 per cent. of his fees from all patients I sent him. Another said he would do the square thing and give me 33 per cent. The third, and not the least, so far as his reputation as an operator and writer, offered me 50 per cent. of all fees. These same specialists have given their opinion freely at medical meetings, denounced the general practitioner and placed him alongside the crook. If all surgeons and specialists who have been so free to denounce the practice are playing the double game it is time to correct the would-be honest surgeon and place him where he should be. For my part I think he has played the part of the wolf long enough. I feel sure that I am not the only physician doing general work who has had such propositions.

ILWIS S. Eastlake, M.D.

\section{Castor-Oil in Neuralgia.}

New Yoki City, April 26, 1900

To the Editor:-In the discussion on castor-oil in the treatment of neuralgia, I note (see THE JournaL of April 21, p. 982) that Dr. Paddock is troubled to know how the oil can be given, while Dr. Fütterer tells of giving it with alcoholics that may in some degree interfere with its usefulness; and Dr. Hirst is quoted as advising that it be given in warm milk, while the question is raised as to how warm milk disguises the taste of the oil.

Some fifteen years ago I not only gave to the profession the fact that cold milk is the best of all vehicles in which to administer both castor-oil and cod-liver oil, but also pointed out the method of administration with the reasons for the method used.

Milk, like these two oils, is an oil or, more properly speaking, an emulsion-and just here let me say that it is Nature's emulsion and, in a very short time, when allowed to stand, it separates, hence the uselessness of all emulsions made by men, for all separate and are a snare and a delusion. Few if any of the emulsions contain the amount of oil that is claimed for them, hence the stomach tolerates the supposed amount of oil better than the amount given when we measure out the oil ourselves.

The method I gave is this: fill the mouth with milk and hold it there; dip up a tablespoonful of milk and pour into this spoon-already full of milk-about a teaspoonful of oil; whether cod-liver oil or castor-oil, you will see that it displaces milk to the extent of its bulk, as any other liquid would do, but the globules of either of these oils, being different from the gobules in milk, do not mix with the latter, and the oil will be in a round ball, not touching the spoon. As you swallow the milk that has been held in the mouth, take the spoonful of milk in the mouth and at once begin to drink milk from a cup at hand. I have never yet found the person who, if the procerlure 
was carried through in this manner, could tell whether he had taken castor-oil or cod-liver oil, or taken none at all. There is absolutely no contact with the mouth or throat, of any particle of the oil, nor can it be smelled on the spoon. All this implies taking immediately, but not with undue haste.

The oils as well as the milk must be cold and the colder the better. The quantity can be increased by degrees as the stomach will stand the oil desired, but if a large dose of castor-oil is desired, it can be given better by repeating the procedure than by attempting to swallow too much at one time.

This procedure has given me and so many of my patients, especially parents when administering oils to children, so much comfort that I repeat what I wrote over fifteen years ago, hoping others who do not seem to have heard of it in detail may also find relief from the nauseous taste that so many dread.

Yours respectfully,

WiCKES WASHBURN, M.D.

\section{Association 2Tews.}

The Official Program.-In order to avoid misunderstandings and to protect the interests of advertisers, attention is called to the fact that there is but one official program. This program is copyrighted by the Board of Trustees and contains no advertising matter.

Delegates to the Meeting of the American Medical As sociation.--Secretaries of societies are requested to forward the names of delegates as soon as possible after these are appointed or elected. George H. Simmons, M.D., Secretary, 61 Market St., Chicago.

General Business Committee.-The first meeting of the General Business Committee of the American Medical Assocration will be held at the Hotel Dennis, Atlantic City, N.J., on Monday afternoon, June 4, at 4:30 o'clock. Subsequent meetings of the Committee will be held at the same place and hour, every afternoon, during the meeting of the Association, unless otherwise directed by the Committee. In order that the business of the Associatron may be effectively transacted, it is very important that all the members of the Committee should attend all its meetings. L. DUNCAN BuLkLEY, Acting Secretary.

Entertainment of Members of the Association.-The Directors of the Philadelphia County Medical Society, aware of the large number of physicians who will pass through Philadelphia on their way to and from the meeting of the AMERICAr Menical Association, to be held at Atlantic City, N. J., June 5 to 8 , and desirous of affording them an opportunity to visit the various hospitals and scientific institutions of Philadelphia, and to witness operations, etc., will establish a bureau of information for the furtherance of these objects. This will be at the College of Physicians of Philadelphia, northeast corner of Thirteenth and Locust Streets, the College having kindly placed a room in its hall at the disposal of the Philadelphia County Medical Society. This room will be in charge of a competent physician, and open from 10 a.m. until 5 p.m., daily except Sunday, from Monday, June 2, to Monday, June 11. Physicians are invited to make free use of the bureau, where they may obtain full information relative to the situation of the various hospitals, medical colleges, and other scientific institutions of Philadelphia, and to the time of operations and clinics at the different hospitals throughout the city. Information will be secured and tabulated daily, showing the leading attractions for that day. The College of Physicians of Philadelphia has also voted to extend to the members of the AMErican MEdical Association the courtesies of the library and of the Muitter museum. The library, which was founded in 1788 , is, with the single exception of that of the surgeon-general's office in Washington, D. C., the largest collection of medical books in this country. The Mütter museum, which was endowed in 1856, by the late Prof. Thomas D. Muiter, contains about 4000 specimens of normal and pathologic anatomy, besides valuable models, easts, and illustrated anatomic works. Both the library and the museum will also be open from 10 a.m. to 5 p.ni., laily except Sundav. Additional information may be secured by addressing the Bureau of Information, at the address above, from June 2 to 11 , and prior to that time by addressing any of the directors of the Philadelphia County Medical Society, as follows: Drs. A. O. J. Kelly, Chairman, No. 1911 Pine Street, Chas. A. Oliver, John G. Clark, Addinell Hewson, or Emma Musson.

\section{Deaths and Dbituaries.}

S. G. Plummer, M.D., Rock Island, Ill., died April 29, aged 79 years. He was born in Pennsylvania, received his early education in the Greenville ( $\mathrm{Pa}$.) Academy, and the Western Reserve College in Ohio. In 1856 he was graduated from the Cleveland Medical College, and in 1861 was made surgeon of the Thirteenth Ill. Vol. Inf., Iater appointed medical director of the First Division, Fifteenth Army Corps, and made its surgeon. Since the Civil War, he had practiced medicine in Rock Island, where he served on the medical staff of St. Anthony's Hospital. He was a member of the American Medical Association, the Illinois State Medical Society, and the Iowa and Illinois Central Medical Association.

M. M. BAGG, M.D., died May 2, in Utica, N. Y., aged 89 years. He studied in Hamilton College; in 1833 went to Yale, where he was graduated four years later, and in 1842 received his degree in medicine from the Geneva Medical College. After a year spent in Paris, he returned to Utica, where he had since practiced. He was a trustee of Faxton Hospital and a member of its board of physicians, was also on the consulting staff of St. Iuke's Hospital and one of the visiting physicians to the Utica Orphan Asylum.

Leander H. Baker, M.D., Louisville, (Ky.) Medical College, died May 4, of bronchitis, at his home in Oak Park, Ill. He practiced medicine in St. Louis, Mo., until the breaking out of the Civil War, when he was appointed surgeon of the Twenty. fourth Mo. Vol. Inf. In 1864 he located in Quincy, Ill., and from there went to Payson, Ill., thence to Oak Park.

Jonn Stockтon Hovgh, M.D., a retired physician, died at his home in Ewing, near Trenton, N. J., May 6, aged 54 years. He was graduated from the Pennsylvania University's medical department, and had traveled extensively in Europe in the interest of his profession. He was also one of the best known men in New Jersey, a bibliographer possessed of a large library, and of late years was active in the movements for good roads. His death resulted from injuries received by having been thrown from his carriage a week previously.

RICHARD H. KealHofER, M.D., aged 50, died suddenly of heart disease, in Philadelphia, May 1. He was a resident of Hagerstown, Md., and had been on a trip to Atlantic City. Dr. Kealhofer was educated at Franklin and Marshall College, studied medicine with Dr. J. McPherson Scott, of Hagerstown, and received his degree at the University of Maryland in 1866. He practiced for a time in St. Louis, Mo.

BenJamin Geret, M.D., St. Charles, Mo., died May 3, aged 58 years. He was a native of Bavaria, and in 1868 was graduated from the Royal College of Medicine at Erlangen; later he was appointed a major-surgeon in the German army, and was decorated with high honors by both the king of Bavaria and the emperor of Germany.

G. R. C. Topd, M.D., a brother-in-law of Abraham Lincoln, and a surgeon in the Confederate Army during the Civil War, died at his home-in Barnwell, S. C., April 25. He was graduated from the medical department of the Transylvania University, Lexington, $\mathrm{Ky}$., in 1850 .

Charles H. Mesereau, M.D., College of Physicians and Surgeons, New York City, 1884, died of cardiac disease at his home in New York City, May 4, aged 37 years. For two years he was a house-surgeon in the Hartford (Conn.) Hospital, and was for several years a sanitary inspector of the New York Health Board.

John P. Landon, M.D., died at his home in Tilleride, Colo. recently. He was graduated from the Bellevue Hospital Medical College, New York City, in 1875, and practiced in Sterling, Ill., for a number of years before going West. 